\title{
Comparative study of anthropometric measurement and body composition between junior handball and basketball players from the Serbian national league
}

\author{
Masanovic B.D. ${ }^{1 \mathrm{ABCDE}}$, Bavcevic T.T. ${ }^{2 \mathrm{ABCD}}$, Prskalo I.A. ${ }^{3 \mathrm{ABDE}}$ \\ ${ }^{1}$ Faculty for Sport and Physical Education, University of Montenegro, Montenegro \\ ${ }^{2}$ Faculty of Kinesiology, University of Split, Croatia \\ ${ }^{3}$ Faculty of Teacher Education, University of Zagreb, Croatia
}

Authors' contribution: A - Study design; B - Data collection; C - Statistical analysis; D - Manuscript Preparation; E - Funds collection.

\begin{abstract}
Purpose: $\quad$ The purpose of this study was to describe anthropometric characteristics and body composition of junior handball and basketball players from the Serbian National League, as well as to make a comparison between them.

Material: $\quad$ Sixty male athletes were enrolled in the study and they were divided into three groups: fifteen handball players, thirteen basketball players and thirty-two healthy sedentary subjects. All subjects were assessed for the anthropometric measures required for calculation of body composition variables, using standardized procedures recommended by previous studies. Data were analyzed using SPSS software and descriptive statistics was expressed as a mean (SD) for each variable, while the ANOVA and LSD Post Hoc tests were carried out to detect the effects of each type of sport.

Results: $\quad$ The results showed there was no significant difference in body weight, body mass index or in bone content, while a significant difference was found in body height as well as in muscle mass and body fat.

Conclusions: These findings may give coaches from the region better working knowledge, and suggest to them to follow recent methods of selection techniques and to be more careful during the process of talent identification.

Keywords: $\quad$ sport, junior, handball, basketball, male.
\end{abstract}

\section{Introduction}

Researchers all over the world are trying to find a formula to improve the performance of athletes and to discover talents as efficiently as possible [1]. They are trying to determine strengths and weaknesses, assigning player positions and helping in designing optimal training programmes [2]. However, most authors give priority to investigating issues such as increasing physical fitness of athletes rather than considering the assessment of their body composition and their nutritional status [3]. The basic goal of the contemporary scientific access in the area of sport sciences is to recognize the standard performance of players of all ages, and to recognize and use talents as early as possible. Identification is very demanding, as various sporting events require differing body types to achieve maximum performance [4]. For this reason, understanding body composition of athletes, and then assigning corresponding competitive weights of athletes, has been done for decades and is considered to be an essential part of the entire management process [1]. However, children and adolescent athletes grow in a manner similar to non-athletes and it is well known that adequate profiling is of the greatest importance in various sports. It is so due to the reason that absolute size significantly contributes to the success in sport [5].

Anthropometrical characteristics and body composition of athletes have been the subject of many investigations as many researchers concluded that through a long process of systematic training, the (c) Masanovic B.D., Bavcevic T.T., Prskalo I.A., 2019 doi:10.15561/18189172.2019.0206 organism, in morphological and functional sense, adapts to exposed influences [6]. Top level athletes might be expected to exhibit characteristics that are specifically favorable for a sport [7]. All competitive sports played at the professional level require that the body performs to its optimal biomechanical and physiological capacity [8]. Correct assessment of body composition in sports is important since errors may lead to mistakes in training prescription and diet elaboration, and therefore affect athletic performance [5]. Adequate body composition and body mass, among other factors, contribute to optimal exercise routines and performance [9]. Some sports, such as martial arts, require much more knowledge regarding this topic than others due to weight limits related to the set standards. In sports like handball or basketball for example, it is well known that excessive fat mass compromises physical performance, while increased muscle mass is important to improve strength and power, which is relevant to athletic performance [10]. An excess of fat mass acts as dead body mass in activities where the body must be repeatedly lifted during locomotion and jumping, decreasing performance and increasing energy demands [2]. For most sports, it is a remedial ballast, but in some sports it is necessary [11]. However, skeletal muscle mass is an indicator of sports performance, because it contributes to the energy production during high-intensity activities and provides absolute strength for athletes [12]. From this follows a conclusion that a modern athlete should be fast, develop explosive strength and overall power. He should have more muscle mass and 
less fat tissue.

However, most of the data regarding characteristics of handball and basketball players come from America and Western Europe. There is a lack of data from Eastern Europe, especially the Western Balkan region, where population in general has specific measurements [13]. Hence, the aim of this study is to find out if data collected regarding anthropometrical characteristics and body composition of Western Balkan athletes support previous studies that have evaluated ideal anthropometric profiles of successful handball players [14, 15] and basketball players $[9,16]$. In these previous researches which provide insights into the requirements for competing at the top level in particular sports we come across certain differences. Handball is a team sport played in an indoor field and requires a high standard of aerobic and anaerobic fitness in order to complete 60 minutes of a competitive game and achieve success through an intermittent high intensity body-contact and well-coordinated activities [17]. One of the fastest and the most endurance required team sports and is formed by special maneuvers such as handball is jumping, shooting under the pressure, faking against hard defense players and attempting fast breaks despite all the fatigue [14]. On the other hand, basketball is a team sport that is also played in an indoor field which is smaller than a handball field. It requires a high level of preparation in order to complete 40 minutes of competitive game and to achieve success [5]. Basketball has been described as an intermittent sport, being physically very demanding, requiring players to permanently repeat bouts of intense actions (sprinting, shuffling, jumping) with jogging, walking, or short periods of recovering between them [18]. In this game, movement patterns significantly differ from those in handball. They require speed and explosiveness for using basketball techniques such as rebounding, driving, lay-ups, jump shooting, shot blocking, fast breaks and a high speed play. Also, the average work intensity of a basketball game is above $85 \%$ of maximal heart rate and VO max values are above $80 \%$ [9].

Hence, the purpose of this study was to describe anthropometric characteristics and body composition profiles of elite junior handball and basketball players from the Serbian National League and to detect possible differences in relation to the competition level.

\section{Materials and Methods}

Participants: Sixty male athletes were enrolled in the study. They were divided into three groups: fifteen handball players ( $16.93 \pm 0.59 \mathrm{yrs}$.) from the Serbian Junior Premier League, thirteen basketball players (17.08 \pm 0.28 yrs.) from the Serbian Junior Premier League and thirtytwo healthy sedentary subjects from the same country $(17.34 \pm 0.60$ yrs.). The measurements were carried out in the winter preparation period.

Procedure: All subjects were clinically healthy and had no recent history of infectious disease, asthma or cardio-respiratory disorders. All of them gave their written consent and the local ethics committee approved the protocol of the study. All subjects were assessed for anthropometric measures required for the calculation of body composition variables. It was used the standardized procedure recommended by the International Biological Program (IBP) standards respecting the basic rules and principles related to the parameter choice, standard conditions and measurement techniques, and the standard measuring instruments, adjusted before the measurement was carried out. Height and weight were measured in the laboratory with subject dressed in light clothing. Height was measured to the nearest $0.1 \mathrm{~cm}$ using a fixed stadiometer, and weight was measured to the nearest $0.1 \mathrm{~kg}$ with a standard scale utilizing a portable balance. Body mass index (BMI) was calculated as body mass in kilograms divided by height in meters squared $(\mathrm{kg} / \mathrm{m} 2)$. Skinfolds $(\mathrm{mm})$ were measured at six sites: triceps skinfold thickness, forearm skinfold thickness, thigh skinfold thickness, calf skinfold thickness, chest skinfold thickness and abdominal skinfold thickness (using a skinfold caliper). Every single measurement and the sum of the six measurements were used for the analysis. The circumferences of the upper and lower arm, and the upper and lower leg were measured in centimeters and the following diameters were measured to the nearest $0.1 \mathrm{~cm}$ : elbow diameter, wrist diameter, knee diameter, ankle diameter, upper arm diameter, forearm diameter, thigh diameter, and calf diameter. To reduce measurement variation, the same investigator examined all of the subjects.

Statistical analysis: Data obtained from this research was processed using software SPSS 20.0, adapted to be used on a personal computer. Descriptive statistics was used to compute the mean (SD) for each variable. Analysis of variance (ANOVA) and the LSD Post Hoc test were carried out to detect the effects for each type of sport (handball or basketball) on each variable: body height, body weight, body mass index (BMI), muscle mass, bone content and body fat, as well as to monitor them in sedentary subjects. The significance was set at an alpha level of 0.05 . The analysis was performed using the Statistical Package for Social Sciences (SPSS) version 20.0. Means and standard deviations (SD) were obtained for both anthropometric variables. A comparison of means of sitting height between genders was performed using the t-test. The relationships between stature and sitting height were determined by using simple correlation coefficients at ninety-five percent confidence interval. Then, a linear regression analysis was carried out to examine the extent to which the sitting height can reliably predict stature. Statistical significance was set at $\mathrm{p}<0.05$.

\section{Results}

Anthropometric characteristics of subjects are shown in Table 1. No significant differences were found in body weight, body mass index and bone content among the groups, while a significant difference was found for body height $(\mathrm{F}=22.75)$ and the other two variables among the groups: muscle mass $(\mathrm{F}=4.27)$, and body fat $(\mathrm{F}=5.36)$.

Significant differences of anthropometric characteristics among particular sports are shown in Figure 1. 
Table 1: Descriptive data and ANOVA

\begin{tabular}{lllll}
\hline Variables & Handball $(\mathbf{N}=15)$ & \multicolumn{1}{l}{ Basketball $(\mathbf{N}=13)$} & Control (N=32) & ANOVA \\
\hline & & \multicolumn{4}{l}{ Mean \pm Standard Deviation } \\
Height $(\mathrm{cm})$ & $181.51 \pm 5.33$ & $193.60 \pm 7.70$ & $178.26 \pm 7.27$ & $0.000^{*}$ \\
Weight $(\mathrm{kg})$ & $74.73 \pm 10.17$ & $80.00 \pm 9.76$ & $70.27 \pm 14.09$ & $0.060^{\wedge}$ \\
BMI $(\mathrm{kg} / \mathrm{m} 2)$ & $22.66 \pm 2.83$ & $21.32 \pm 1.99$ & $22.11 \pm 4.27$ & $0.610^{\wedge}$ \\
Muscle content of body (\%) & $48.85 \pm 4.03$ & $49.81 \pm 2.58$ & $46.95 \pm 3.02$ & $0.019^{*}$ \\
Bone content of body (\%) & $17.03 \pm 2.49$ & $16.95 \pm 1.15$ & $17.34 \pm 2.47$ & $0.836^{\wedge}$ \\
Fat content of body (\%) & $16.39 \pm 3.28$ & $12.48 \pm 3.67$ & $19.09 \pm 7.77$ & $0.007^{*}$ \\
\hline
\end{tabular}

Note: $\mathrm{N}$ - number of subjects; BMI - body mass index; ^ - non-significant; ${ }^{*}$ - significant difference between groups.
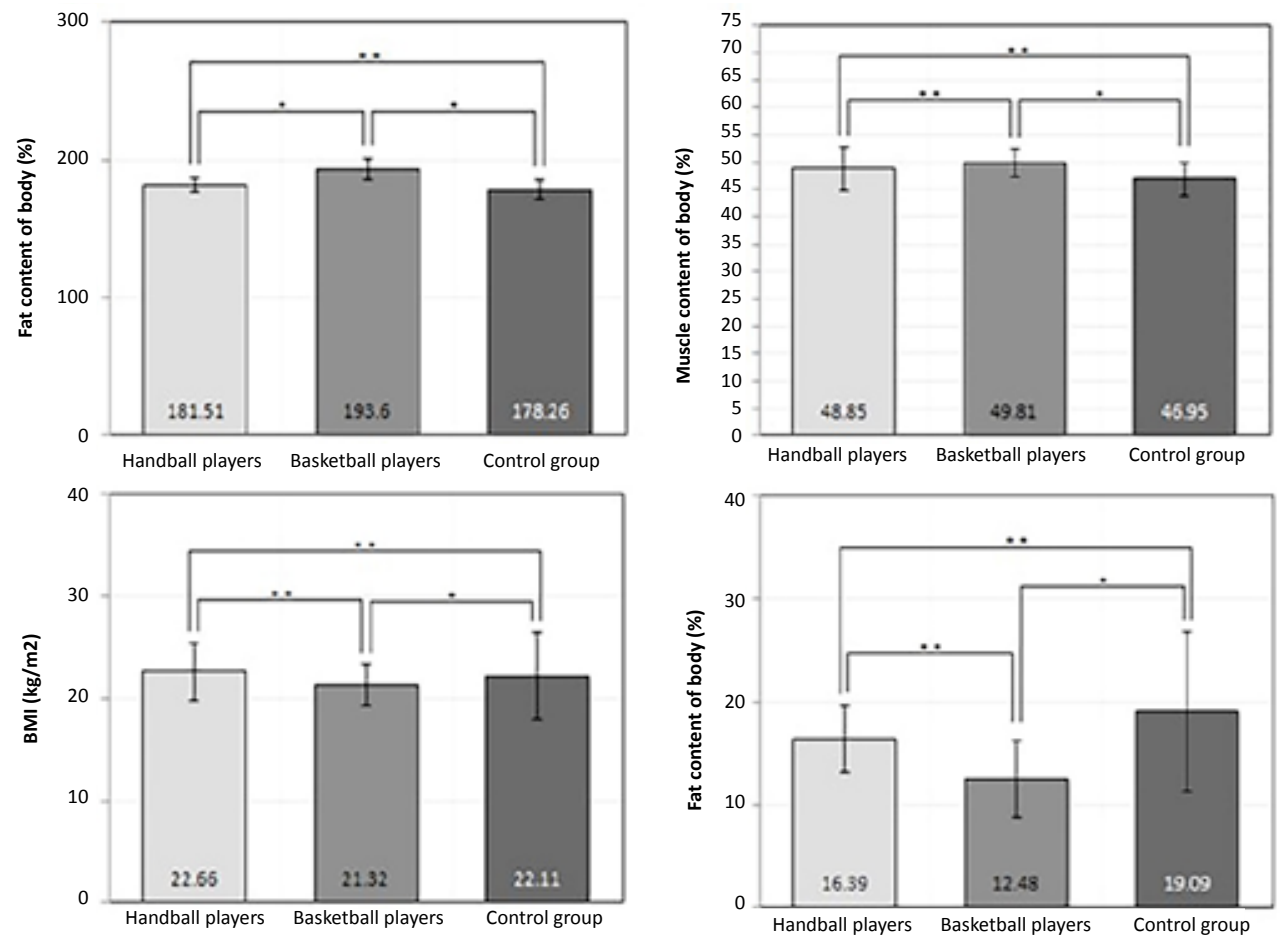

Legend: * - significance; **-non-significance.

Figure 1. LSD Post Hoc test for the different parameters among the subjects

The LSD Post Hoc test indicates that basketball players were significantly taller than handball players and subjects from the control group, while there was no significant difference in height of handball players and height of subjects from the control group. This test also indicated that basketball players were significantly heavier than subjects from the control group, while there was no significant difference in weight between handball players and the other two groups. As far as muscle mass of the subjects is concerned, it was significantly lower in subjects from the control group than in all other subjects, while no difference was found regarding this variable between handball and basketball players. Lastly, basketball players had significantly less body fat than subjects from the control group while no other differences were found in regard to this variable.

\section{Discussion}

These results support previous investigations indicating a significant difference regarding the body height among the basketball players on one side, and handball players and subjects from the control group that represents the general population on the other side $[9,14]$. Thus, the selection criteria, different type of play and game rules between basketball and handball game can explain the noticed differences. Height of handball players obtained in this study raise doubts that the selection process has been carried out correctly. The reason is because official statistical data proved that handball players from Serbia are shorter than the most successful players from teams playing in the IHF Men's Youth World Championship, Russia 2015. For example, the average height of French handball team players was 191.8 centimeters (the winning team), while the 13th 
Korea had the average of 183.4 centimeters, 19th Poland had the average of 190.1 centimeters and the 20th Japan had the average of 181.7 centimeters. However, the teams from Africa and Asia are comparably shorter than the majority of the European teams, and players from Serbia have similar heights, but these teams fail to have good results. Serbian players have not been on the winning streaks in recent years, and this fact gives us one of the reasons. Therefore, this doubt may give Serbian coaches better working knowledge for this group of athletes and suggest them to be more careful during the recruitment as they have a very tall population in general [19]. It is well known that the density including very tall subjects appears to be characteristic of people from this area (Western Balkan), since a high percentage of people from general population was measured at 190 centimeters or more $[20,21]$. On the other hand, the average height of 2016 FIBA U17 World Basketball Championship players, championship played in Zaragoza in Spain, was 195.56 $\mathrm{cm}$. Also, the average height of players from the national basketball team who played semifinals, according to the available data from the official website, were as follows: the USA $(198.17 \mathrm{~cm})$, Turkey $(195.75 \mathrm{~cm})$, Lithuania $(198.17 \mathrm{~cm})$ and Spain $(195.92 \mathrm{~cm})$. These official statistical data proved that the players from the Serbian Basketball Premier League are tall enough and they do not lag behind the top world players. However, this is not a surprise if we consider conclusions about height taken from the previously research witch say that Serbia have a very tall population in general $[19,21]$. Furthermore, it was expected that basketball players were heavier than handball players and the subjects from the control group, mostly due to the reason they are significantly taller than subjects from the both mentioned groups. However, the reason why basketball players significantly are heavier than subjects from the control group can be supported with the fact that the average size of basketball players has increased dramatically in the past decades. This could be a result of better nutrition, especially in professional basketball leagues, partly due to the use of nutritional supplements. The body mass index (BMI; weight/height2) is a parameter that is widely used in adult population, that is it is an internationally recognized definition of overweight and obesity. Fortunately, body mass index of subjects from all three groups was in within the normal limits of weight according to previous research, and there were no significant differences among the groups.

Indeed, it was found that muscle mass of handball and basketball players was significantly higher than in subjects from the control group. These results may be also explained with growing demands to grow muscle mass in sports where intermittent activities are required, and when high intensity activities are followed by low-intensity type of movements [17], such as handball, basketball, etc. While no significant differences were found for bone content among the groups, it is all in accordance with the results obtained by previous studies. Moreover, it was expected that the percentage of body fat of subjects from the control group is significantly higher than the percentage of body fat of basketball players, and these results could be explained by less physical activity in control [1] However, it is interesting that the percentage of body fat of handball players was insignificantly lower than the percentage of body fat of subjects from the control group. These results may be explained by an increased aerobic activity of basketball players, whereas handball training sessions include more anaerobic activity than basketball training sessions, as this game requires higher intensity body-contact and well-coordinated activities [17]. Although handball matches have duration of 60 minutes divided in two halves lasting 30 minutes each, handball players cover a total distance ranging approximately from 2,000 to 6,000 meters $[22,23]$. This is a shorter distance $(5,000$ to 7,000 meters) than the one covered by basketball players [5], although basketball matches have duration of 40 minutes divided in four parts lasting 10 minutes each. These distances are based upon different circumstances in each sport. First of all, it depends on the positions, then tactical defense or offensive characteristics, and finally on characteristics of the game itself.

Furthermore, it is very important to remember that athletes from elite team sports such as handball and basketball, need a certain percentage of body fat to perform well enough and achieve their full playing potential. Body of people who have too little fat tissue are exposed to certain risks. Excessive decrease of fat levels can lead to complications and contraindications. Adipose tissue is a complex, essential, and highly active metabolic and endocrine organ, which responds to afferent signals from traditional hormone systems and the central nervous system, and expresses and secretes factors with important endocrine functions [24]. In addition to energy storage, it also regulates energy metabolism via secreting adipokines into the circulation [25]. These bioactive peptides (Leptin, Adiponectin and Interleukin 6), which synthesized in adipose tissue [26] regulate various functions. Endocrine effects of leptin include regulation of immune function, proliferation, hematopoiesis, angiogenesis, and it also stimulates endothelial cell growth and angiogenesis, accelerates wound healing, and play an important role in the bone development [26]. Adiponectin has anti-diabetic, anti-inflammatory and anti-atherogenic properties [27]. Interleukin 6 helps to regulate responses to the trauma, especially burns and other damaged tissues that lead to inflammation [28], and it is necessary for resistance against Streptococcus pneumoniae. Its lack would weaken the organism, also it was discovered that its concentration is significantly increased during training, and it precedes the occurrence of other cytokines in the circulation [29]. It is thought to act as a hormone that mobilizes extracellular substances and changes the delivery of the substrate during physical activity. Through this interactive network, adipose tissue is integrally involved in coordinating a variety of biological processes including energy metabolism and immune function [30]. Thus, both excess and deficiency of adipose tissue have harmful metabolic consequences, and represent significant medical and socioeconomic burdens in the world today. The National 
Strength and Conditioning Association indicates that body fat percentages vary from less than 7 percent to 17 percent among male athletes, depending on the sports discipline. However, we would like to point out that these are just guidelines and athletes should work closely with their coaches and their personal physicians to determine an appropriate body fat percentage to enhance both physical abilities and health.

\section{Conclusion}

This study suggests that playing handball (slightly) and basketball (significantly) decreased the percentage of body fat and significantly increased the percentage of muscle mass (using the comparison of the control group, in which the participants had a higher percentage of body fat and lower percentage of muscle content). The part attributed to the body height is the main cause of selection process. Hence, it is rather important to focus on these variables as they resulted as essential. On the other hand, while differences in body weight are highly influenced by specific nutritional habits, training and supplements, there are no differences for bone content and body mass index regarding a healthy lifestyle and nutritional habits in subjects from the control group.

Considering that the measurements were conducted in the middle of the season, this study is limited because changes in body composition and physical performance may occur from the start to the end of competitive season [31]. Accordingly, further studies should be very careful in projecting timelines for measuring anthropometric characteristics and body composition, mostly due to the fact that it has to be conducted either at the beginning or at the end of a season. It also has to be explicitly reported when the measurement is conducted exactly.

\section{Conflicts of interest}

The authors declare no conflict of interest.

\section{References}

1. Popovic, S, Bjelica D, Jaksic D, Hadzic R. Comparative Study of Anthropometric Measurement and Body Composition between Elite Soccer and Volleyball Players. International Journal of Morphology. 2014; 32(1): 267-274. https://doi.org/10.4067/S0717-95022014000100044

2. Masanovic B, Milosevic Z, Corluka M. Comparative Study of Anthropometric Measurement and Body Composition between Junior Handball and Volleyball Players from Serbian National League. International Journal of Applied Exercise Physiology. 2018; 7(4):1-6.

3. Triki M, Rebai H, Abroug T, Masmoudi K, Fellmann N, Zouari M, Tabka Z. Comparative study of body composition and anaerobic performance between football and judo groups. Science and Sports. 2012; 27(5): 293-299. https://doi.org/10.1016/j.scispo.2011.07.004

4. Krespi M, Sporis G, Popovic S. Exponential versus linear tapering in junior elite soccer players: effects on physical match performance according to playing positions. Montenegrin Journal of Sports Science and Medicine. 20191;8(1):17-22. https://doi.org/10.26773/mjssm.190303

5. Popovic S, Akpinar S, Jaksic D, Matic R, Bjelica D. ComparativeStudy ofAnthropometric MeasurementandBody Composition between Elite Soccer and Basketball Players. International Journal of Morphology. 2013; 31(2): 461-467. https://doi.org/10.4067/S0717-95022013000200016

6. Masanovic B. Comparative study of anthropometric measurement and body composition between junior basketball and volleyball players from Serbian national league. Sport Mont, 2018; 16(3): 19-24. https://doi.org/10.26773/smj.181004

7. Hulka K, Weisser R. The Influence of the Number of Players on Workload during Small-Sided Games among Elite Futsal Players. Montenegrin Journal of Sports Science and Medicine, 2017; 6(1):45-48.

8. Leonardi TJ, Paes RR, Breder L, Foster C, Goncalves CE, Carvalho HM. Biological maturation, training experience, body size and functional capacity of adolescent female basketball players: A Bayesian analysis. International Journal of Sports Science \& Coaching. 2018;13(5):713-722. https://doi.org/10.1177/1747954118772489

9. Pena J, Moreno-Doutres D, Coma J, Cook M, Busca
B. Anthropometric and fitness profile of high-level basketball, handball and volleyball players. Revista Andaluzade Medicina Del Deporte, 2018; 11(1): 30-35. https://doi.org/10.1016/j.ramd.2016.03.002

10.Ramos-Campo DJ, Martinez-Sanchez F, EstebanGarcia P, Rubio-Arias JA, Bores CA, Clemente-Suarez VJ, Jimenez-Diaz JF. Body Composition Features in Different Playing Position of Professional Team Indoor Players: Basketball, Handball and Futsal. International Journal of Morphology. 2014; 32(4): 1316-1324. https://doi.org/10.4067/S0717-95022014000400032

11.Jagiello W, Jagiello M, Kalina RM, Barczynski BJ, Litwiniuk A, Klimczak J. Properties of body composition of female representatives of the Polish national fencing team - the sabre event. Biology of Sport. 2017;34(4):401-406. https://doi.org/10.5114/biolsport.2017.70526

12.Popovic S. Local Geographical Differences in Adult Body Height in Montenegro. Montenegrin Journal of Sports Science and Medicine. 2017; 6(1):81-87.

13.Bjelica D, Popovic S, Kezunovic M, Petkovic J, Jurak G, Grasgruber P. Body Height and Its Estimation Utilizing Arm Span Measurements in Montenegrin Adults. Anthropological Notebooks. 2012; 18(2):69-83.

14.Chaouachi A, Brughelli M, Levin G, Boudhina N, Cronin J, Chamari K. Anthropometric, physiological and performance characteristics of elite team-handball players. Journal of Sports Science. 2009; 27(2): 151-157. https://doi.org/10.1080/02640410802448731

15.Fieseler G, Hermassi S, Hoffmeyer B, Schulze S, Irlenbush L, Bartels T, Delank KS, Laudner K, Schweisg R. Differences in anthropometric characteristics in relation to throwing velocity and competitive level in professional male team handball: A tool for talent profiling. The Journal of sports medicine and physical fitness. 2017; 57(7-8):985-992.

16.Pojskic H, Separovic V, Muratovic M, Uzicanin E. Morphological Differences of Elite Bosnian Basketball Players According to Team Position. International Journal of Morphology. 2014; 32(2): 690-694. https://doi.org/10.4067/S0717-95022014000200051

17.Bilge M. Interval Training Specific to Handball and Training Programme Designs. World Applied Sciences Journal, 2013; 25(7):1066-1077. 
18.Balciunas M, Stonkus S, Abrantes C, Sampaio J. Long term effects of different training modalities on power, speed, skill and anaerobic capacity in young male basketball players. Journal of Sports Science and Medicine. 2012; 5(2):163-70.

19.Popovic S, Bjelica D, Molnar S, Jaksic D, Akpinar S. Body Height and Its Estimation Utilizing Arm Span Measurements in Serbian Adults. International Journal of Morphology. 2013a; 31(1): 271-279. https://doi.org/10.4067/S0717-95022013000100043

20.Masanovic B. Standing Height and its Estimation Utilizing Arm Spam and Foot Length Measurements in Dinaric Alps Population: A Systematic Review. Sport Mont. 2018a; 16(2): 1-6. https://doi.org/10.26773/smj.180619

21.Pineau JC, Delamarche P, Bozinovic S. Average height of adolescents in the Dinaric Alps (in French). Comptes Rendus Biologies. 2005; 328(9): 841-846. https://doi.org/10.1016/j.crvi.2005.07.004

22.Gusic M, Popovic S, Molnar S, Masanovic B, Radakovic M. Sport-Specific Morphology Profile: Differences in Anthropometric Characteristics among Elite Soccer and Handball Players. Sport Mont. 2017; 15(1):3-6.

23.29. Fischer CP. Interleukin-6 in acute exercise and training: What is the biological relevance? Exercise immunology review, 2006; 12(1):6-33.

24.Arifi F, Bjelica D, Masanovic B. Differences in anthropometric characteristics among junior soccer and handball players. Sport Mont. 2019; 17(1):45-49. https://doi.org/10.26773/smj.190208

25.Kershaw EE, Flier JS. Adipose Tissue as an Endocrine Organ. The Journal of Clinical Endocrinology \& Metabolism. 2004; 89(6): 2548-2556. https://doi.org/10.1210/jc.2004-0395
26.Ozenoglu A, Balci H, Ugurlu S, Caglar E, Uzun H, Sarkis C, Gunay C, Eker E. The relationships of leptin, adiponectin levels and paraoxonase activity with metabolic and cardiovascular risk factors in females treated with psychiatric drugs. Clinics. 2008; 63(5): 651-660. https://doi.org/10.1590/S1807-59322008000500014

27.Verdes, G, Duta CC, Popescu R, Mituletu M, Ursoniu S, Lazar OF. Correlation between leptin and ghrelin expression in adipose visceral tissue and clinical-biological features in malignant obesity. Romanian Journal of Morphology and Embryolgy. 2017; 58(3):923-992.

28.SilvaMG,BorbaEF,MelloSB,ShinjoSK. Serumadipocytokine profile and metabolic syndrome in young adult female dermatomyositis patients. Clinics. 2016; 71(12): 709-714. https://doi.org/10.6061/clinics/2016(12)06

29. Marginean CO, Man L, Pitea AM, Man A, Marginean, C, Coto OS. The assessment between IL- 6 and IL- 8 and anthropometric status in malnourished children. Romanian Journal of Morphology and Embryology. 2013; 54(4):935938.

30.Fusaru AM, Stanciulescu CE, Şurlin V, Taisescu C, Bold A, Pop OT, Banita IM, Craitoiu S, Pisoschi CG. Role of innate immune receptors TLR2 and TLR4 as mediators of the inflammatory reaction in human visceral adipose tissue. Romanian Journal of Morphology and Embryology. 2012; 53(3):693-701.

31.Nepocatych S, Balilionis G, O’Neal EK. Analysis of dietary intake and body composition of female athletes over a competitive season. Montenegrin Journal of Sports Science and Medicine, 2017; 6(2): 57-65. https://doi.org/10.26773/mjssm.2017.09.008

\section{Information about the authors:}

Masanovic B.D.; (Corresponding author); http://orcid.org/0000-0002-4939-4982; bojanma@ucg.ac.me; University of Montenegro; Narodne omladine bb, 81400, Niksic, Montenegro.

Bavcevic T.T.; http://orcid.org/0000-0002-5439-8590; tonci.bavcevic@gmail.com; University of Split; Teslina 6, 21000, Split, Croatia.

Prskalo I.A.; http://orcid.org/0000-0003-0087-2805; ivan.prskalo@ufzg.hr; University of Zagreb; Savska cesta 77, 10000, Zagreb, Croatia.

Cite this article as:

Masanovic BD, Bavcevic TT, Prskalo IA. Comparative study of anthropometric measurement and body composition between junior handball and basketball players from the Serbian national league. Pedagogics, psychology, medical-biological problems of physical training and sports, 2019;23(2):90-95.

https://doi.org/10.15561/18189172.2019.0206

The electronic version of this article is the complete one and can be found online at: https://www.sportpedagogy.org.ua/index.php/PPS/issue/archive

This is an Open Access article distributed under the terms of the Creative Commons Attribution License, which permits unrestricted use, distribution, and reproduction in any medium, provided the original work is properly cited (http://creativecommons.org/licenses/by/4.0/deed.en).

Received: 20.02.2019

Accepted: 21.03.2019; Published: 30.04.2019 